\title{
An innovative blended learning approach using virtual patients as preparation for skills laboratory training: perceptions of students and tutors
}

\author{
Ronny Lehmann ${ }^{1 *}$, Hans Martin Bosse ${ }^{2}$, Anke Simon $^{1}$, Christoph Nikendei ${ }^{3}$ and Sören Huwendiek ${ }^{4}$
}

\begin{abstract}
Background: Currently only a few reports exist on how to prepare medical students for skills laboratory training. We investigated how students and tutors perceive a blended learning approach using virtual patients (VPs) as preparation for skills training.

Methods: Fifth-year medical students ( $N=617$ ) were invited to voluntarily participate in a paediatric skills laboratory with four specially designed VPs as preparation. The cases focused on procedures in the laboratory using interactive questions, static and interactive images, and video clips. All students were asked to assess the VP design. After participating in the skills laboratory 310 of the 617 students were additionally asked to assess the blended learning approach through established questionnaires. Tutors' perceptions $(\mathrm{N}=9)$ were assessed by semi-structured interviews.

Results: From the 617 students 1,459 VP design questionnaires were returned (59.1\%). Of the 310 students 213 chose to participate in the skills laboratory; 179 blended learning questionnaires were returned (84.0\%). Students provided high overall acceptance ratings of the VP design and blended learning approach. By using VPs as preparation, skills laboratory time was felt to be used more effectively. Tutors perceived students as being well prepared for the skills laboratory with efficient uses of time.
\end{abstract}

Conclusion: The overall acceptance of the blended learning approach was high among students and tutors. VPs proved to be a convenient cognitive preparation tool for skills training.

Keywords: Medical education, Skills laboratory, Virtual patients, Blended learning

\section{Background}

Teaching medical procedures to large numbers of students often involve simulations in skills laboratories, which have become increasingly popular worldwide $[1,2]$. Skills laboratories enable the teaching of procedures in a standardised and structured manner to improve procedural skills performance [3]. Students usually get some kind of instruction and demonstration, such as use of Peyton's four-step approach [4], training supervised by tutors, and feedback. Skills laboratory training usually includes both for students: knowledge of what should be done and how to do it, and repetitive practice under supervision. To be effective only a few students in

\footnotetext{
* Correspondence: ronny.lehmann@med.uni-heidelberg.de

${ }^{1}$ Clinic I - General Paediatrics, Centre for Child and Adolescent Medicine, Im Neuenheimer Feld 430, Heidelberg 69120, Germany

Full list of author information is available at the end of the article
}

small groups can be closely supervised at the same time to provide individual feedback which is of key importance [1]. This makes skills laboratory training quite expensive and resource intensive. To most efficiently use the precious time for skills laboratory training, and to accord with simple-to-complex-ordering of learning tasks [5,6], it is helpful if students are well prepared before attending training. Effective preparation might allow during the skills laboratory session a focus on practicing and providing repeated feedback instead of using the time for instruction. To our knowledge, mainly paper handouts are used for skills laboratory preparation of students [7]. There are few data concerning methods to prepare for skills laboratory training and their effectiveness.

Issenberg et al. reported the following 10 aspects related to a good implementation of effective learning within simulations [1]: providing feedback, repetitively 
practising, integration into the overall curriculum; practising with increasing levels of difficulty; adaption to multiple learning strategies; providing for clinical variation; a controlled environment; providing individualised learning; definitions of outcomes and benchmarks; validation of the learning tools. Of these recommendations, preparation for skills laboratory training was not explicitly addressed; we assume this was because of limited available data. This is consistent with a recent systematic meta-analysis by McGaghie et al. who point out that there is still little understanding regarding how different learning modalities can be integrated to best foster learning [8]. An example of integrating different learning modalities is to supplement face-to-face sessions with e-learning to enhance the effects of learning as Motschnig-Pitrik et Holzinger have shown [9].

Virtual patients (VPs) are a one-of-a-kind e-learning resource where the learner takes the role of a healthcare professional and interactively diagnoses and treats his or her patient [10]. VP approaches usually offer the possibility to embed multimedia such as video and audio clips to illustrate patient findings or procedures. A large variability of designs and approaches has been described [11]. The current literature suggests the main benefit of VPs as primarily promoting clinical reasoning skills [12]. To date VPs have mainly been reported as stand-alone teaching units. Several authors have suggested investigating how to successfully integrate e-learning in general, and VP in particular, into a curriculum [12-15].

Surprisingly, there are only a few reports available comparing different curricular integration scenarios for VPs [16-19]. These authors show that providing VPs on its own results in low acceptance and usage, while the approach is more effective when blended with face-to-face sessions. The scarce literature regarding VPs as a preparation tool mainly focuses on the preparation of communication or physical examination skills [20-22]. The authors of these studies showed that such electronic tools are well accepted among students and that they can improve performance for clinical skills and self-confidence in dealing with real patients. Edelbring et al. reported that VPs can provide a structure in the unstructured environment of a new clinical field for students to get prepared for real patient encounters [23].

Some data are available concerning various other multimedia-based tools as preparation for practising procedural skills, such as video instruction in preparation for resuscitation training or a lumbar puncture $[24,25]$. The ability of these methods to improve participants' medical knowledge and technical skills, such as on cardiopulmonary resuscitation (CPR) performance, is comparable to that of tutor-led discussions. In postgraduate training, VP-like computer-based simulators seem to fill a curricular gap because they offer continuous refreshers of important resuscitation algorithms to large numbers of healthcare professionals [26].

Combining e-learning, such as the work-up of VPs, with face-to-face sessions is referred to as 'blended learning' [27]. Blended learning approaches aim to achieve an optimal benefit by combining different learning modalities. Because there is evidence of VPs promoting helpful cognitive preparation for soft skills learning and the physical examination [20-22], it is surprising that no data are available on the use of VPs as preparation for procedural skills training. We sought to fill this gap by investigating how students and tutors perceive the design and curricular integration of specially designed VPs used as preparation for a skills laboratory training in an innovative blended learning approach. We assumed that being cognitively prepared by VPs in selfstudy would result in a more efficient use of training time in a skills laboratory.

\section{Methods}

\section{Paediatric rotation and participants}

Fifth-year medical students $(\mathrm{N}=617)$ were invited to voluntary participate in skills laboratory training during their paediatric rotation at Heidelberg Medical School. The paediatric rotation consists of a four-week-module composed of lectures, bedside teaching, problem-based learning sessions, skills laboratories, and VPs. Students had to work through different kinds of VPs differentially blended with corresponding teaching activities [28]. At the end of the module student performances were evaluated by an electronic key feature exam [29] and an Objective Structured Clinical Examination (OSCE) [30].

In accordance with national practice in Germany, ethical approval was not required for this type of educational study. However, we affirmed with participants that participation was voluntary, that they would not be able to be identified from the collected data, and that no plausible harm from participation in the study could arise.

\section{Virtual patients}

Four VPs were developed using the CAMPUS shell (www.virtual-patients.com) [31]. The VPs were designed according to published design criteria [28]. Because the cases used in the scenario had a special emphasis on preparation for skills laboratory training and less for fostering clinical reasoning skills, they were specially designed to be short (15-20 $\mathrm{min}$ ) and the focus was on the detailed procedure enhanced by media clarifications including video clips (Figure 1). Themes and emphases of the four cases were:

- VP1: Infant with suspected meningitis, focus on lumbar puncture (informed consent, preparation, performance, and specimen care) 


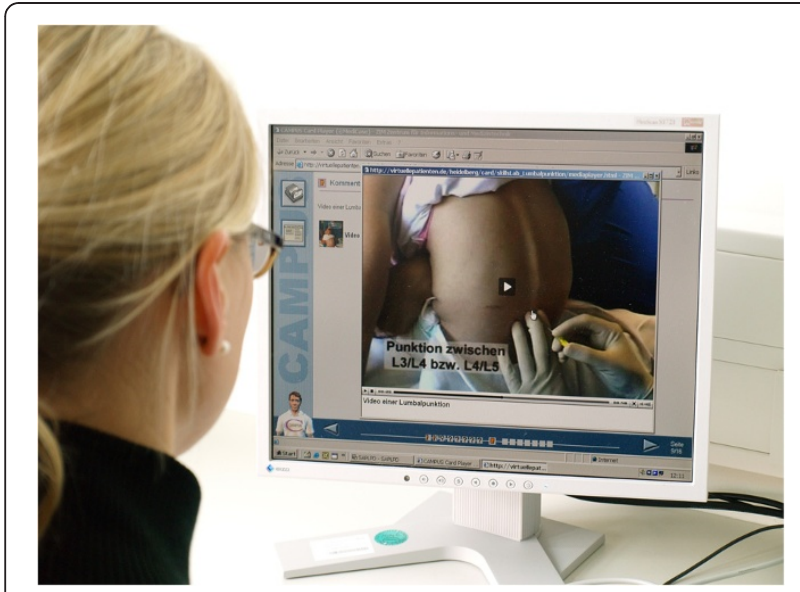

Figure 1 Student using a VP for preparation of infant lumbar puncture. The student works on a short (15 to $20 \mathrm{~min}$ ) and interactive case of a paediatric VP. The focus is on the procedure in detail and is enhanced by media clarifications including video clips.

Table 1 Characterization of VP1 according to [11]

\begin{tabular}{|c|c|}
\hline Title: & Lumbar puncture \\
\hline Description: & $\begin{array}{l}\text { Infant with fever comes to a paediatric } \\
\text { emergency unit. Learner is doctor in charge and } \\
\text { suspects meningitis. A lumbar puncture has to } \\
\text { be indicated, prepared and performed. }\end{array}$ \\
\hline Language: & German \\
\hline Identifier: & SkillsLab - Lumbalpunktion \\
\hline Provenance: & $\begin{array}{l}\text { Lehmann, Bosse, Huwendiek, University of } \\
\text { Heidelberg }\end{array}$ \\
\hline Typical study time: & $15 \mathrm{~min}$ \\
\hline Educational level: & Undergraduate $5^{\text {th }}$ year \\
\hline Educational modes: & Learning and formative assessment \\
\hline Coverage: & Paediatrics \\
\hline $\begin{array}{l}\text { Objectives and } \\
\text { outcome: }\end{array}$ & $\begin{array}{l}\text { Learner will learn indications and } \\
\text { contraindications of a lumbar puncture, what to } \\
\text { prepare and how to perform such puncture. }\end{array}$ \\
\hline Path type: & Linear string of pearls \\
\hline User modality: & $\begin{array}{l}\text { Single user plays the role of the paediatrician in } \\
\text { charge }\end{array}$ \\
\hline Media \& resources: & Text, static graphics, video clips \\
\hline $\begin{array}{l}\text { Narrative use and } \\
\text { patient focus: }\end{array}$ & Told from doctors perspective \\
\hline Interactivity use: & $\begin{array}{l}\text { Multiple choice questions, free text questions } \\
\text { Overall number of cognitive interactions: } 8\end{array}$ \\
\hline Feedback use: & $\begin{array}{l}\text { Feedback is given to each decision immediately } \\
\text { by comparison with the expert decision }\end{array}$ \\
\hline Originating system: & CAMPUS key feature \\
\hline Format: & Interactive Java-Applet inside web-browser \\
\hline $\begin{array}{l}\text { Integration and } \\
\text { dependence: }\end{array}$ & $\begin{array}{l}\text { Java Plug-in respectively Java Runtime } \\
\text { Environment (JRE), CAMPUS backend, otherwise } \\
\text { independent }\end{array}$ \\
\hline
\end{tabular}

- VP2: Infant with suspected urinary tract infection, focus on bladder puncture (informed consent, preparation, performance, and specimen care)

- VP3: Infant with accidental asphyxia, focus on CPR (algorithm, technique)

- VP4: Toddler with cardiac arrest, focus on CPR (algorithm, technique)

The cases were accessible via our web-based learning management platform. The work-up of cases could be checked electronically for each student after completion of each VP case. For details of the cases see the characterisation of VP1 in Table 1 according to the proposed VP typology [11].

\section{Skills laboratory training}

The paediatric skills laboratories are embedded in a longitudinal skills laboratory curriculum of our medical school [7]. Participation in the skills laboratory training was optional to students during the study period but contents were relevant for the summative exam (OSCE) at the end of the clerkship. However, students who chose to participate were required to prepare themselves with the four VPs. Laboratories cover typical paediatric procedural skills, such as suprapubic bladder puncture, lumbar puncture (Figure 2), and paediatric basic life support. Supervision is provided by residents and trained senior medical student tutors. There was no instruction given at the beginning of the skills laboratory, so students were to spend the entire time of the training for repetitive practice under supervision with feedback.

\section{Evaluation instruments}

Students' perceptions were evaluated using two adapted instruments developed by international experts within the Electronic Virtual Patients Project (eViP, www.virtualpatients.eu) [32]. The first focused on the design of VPs while the second surveyed the curricular integration (blended learning) of the VPs. Because the two instruments were developed with a special focus on clinical reasoning some aspects had to be adjusted for these purposes (see below). The modified and added questions were tested for students' understanding using the thinkaloud technique and adjusted accordingly.

\section{Questionnaire for students' perceptions of VP design}

The questionnaire exploring students' perception of the VP design consisted of 15 items (12 items on a Likert scale from $1=$ totally disagree to $5=$ totally agree; 3 open-answer questions) clustered in the following 5 main categories: (i) authenticity (similarity to real life; 2 items), (ii) professional approach (decision making and reasoning; 3 items), (iii) coaching (embedded questions, 


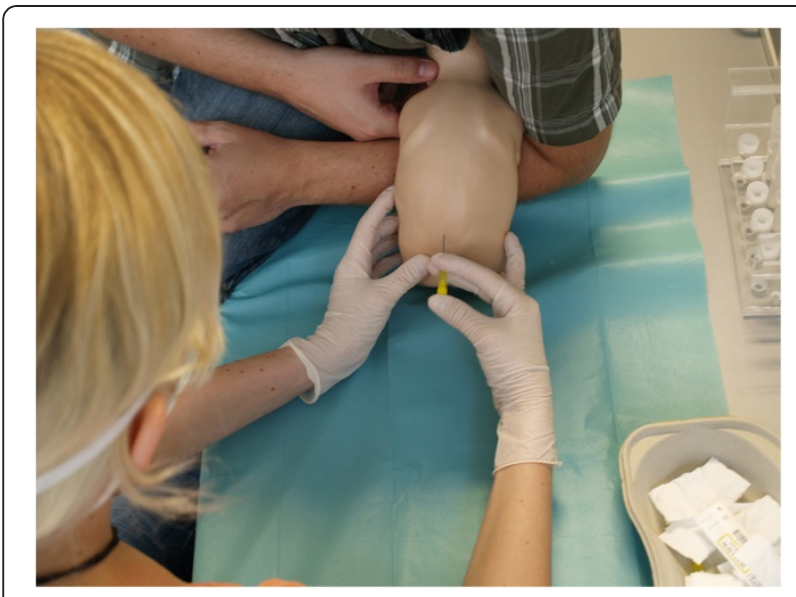

Figure 2 Student practising infant lumbar puncture in the skills lab. The student performs lumbar puncture under supervision of a tutor but without further instructions given at the beginning allowing the entire time of the training to be spent on repetitive practice under supervision with expert feedback.

advice, feedback, and media enhancement for the case; 4 items), (iv) learning effect (2 items), (v) overall judgement $(1$ item). Table 2 presents the list of items used in this study. Questions 7, 8, and 10 were modified from the original tool kit to focus on procedural skills; question 9 was added to specifically assess perceptions of the embedded media. Open-answer questions inquired about specific strengths and weaknesses of the cases, as well as about other comments.

All 617 students were asked to return one questionnaire for each VP (entailing a maximum of 2,468 ) independently of whether they chose to participate in the skills laboratory.

\section{Questionnaire for students' perceptions of the} blended learning scenario

The blended learning questionnaire investigating students' perceptions about how well VP were integrated into the curriculum consisted of 23 items (20 Likertscaled, 3 open-answer questions; Likert scale from $1=$ totally disagree to $5=$ totally agree) in 5 main categories: (i) Teaching presence (the design and management of learning sequences, providing subject matter expertise, and facilitating active learning; 11 items), (ii) cognitive preparation (facilitation of focusing on practising and improvement of practical skills with efficient use of time; 3 items), (iii) social presence (ability of learners to project themselves socially and emotionally within a community of inquiry; 3 items), (iv) learning effect (2 items), (v) overall judgement (1 item). Table 3 shows the list of the items. Questions 10,12,13, and 18 were modified from the original tool kit to focus on the procedural skill. Questions 6 and 14 were added. Open-answer questions were about specific strengths and weaknesses of this kind of curricular integration and about suggestions for better integrations.

Out of the 617 students in the study period, 310 were asked to fill in this questionnaire about the curricular integration of the blended learning scenario after participating in the skills laboratory.

\section{Interviews of skills laboratory tutors}

Skills laboratory tutors' $(\mathrm{N}=9)$ perceptions were obtained by semi-structured interviews focusing on the same issues as addressed in the curricular integration questionnaire. Each interview took about $20 \mathrm{~min}$. The interviews were transcribed, clustered by themes, discussed, and summarised by two of the authors (RL, SH) using content analysis [33].

\section{Statistical analysis}

The questionnaires were analysed using SPSS version 20 (IBM Corporation). Results are given as calculated mean \pm standard deviation of items per category (see Tables 2 and 3 for detailed results).

\section{Results}

During the study period 1,459 VP design questionnaires were returned in total for all 4 VPs by 617 students (59.1\%). 310 out of these 617 students were asked to evaluate the blended learning approach after participating in the skills laboratory. Of these, 213 students chose to participate in the training and 179 blended learning questionnaire forms were returned (84.0\%). The results are presented below.

\section{VP design}

Cases were seen as being authentic $(3.5 \pm 0.8)$ and the professional approach was considered acceptable (3.5 \pm 0.8 . The coaching within the cases was rated as being supportive $(4.0 \pm 0.7)$ with a good learning effect (3.8 \pm 0.7 ). The overall judgement was $4.0 \pm 0.7$ (Likert scales from $1=$ totally disagree to $5=$ totally agree; Figure 3 ). Table 2 shows detailed results of all single items of the questionnaire. In the open-answer questions several students mentioned that the multimedia-based support (video clips and interactive graphics) was in particular helpful. Shortness of the case and focus on clinically relevant aspects were also mentioned as being positive, as were the presentation of typical and realistic scenarios. A few students stated that questions were too specific and that the cases were too linear with predictable results. 
Table 2 VP design questionnaire and results

\begin{tabular}{|c|c|}
\hline Category/items & Result \\
\hline \multicolumn{2}{|l|}{ Authenticity } \\
\hline 1. While working on the virtual patient I felt like making the same decisions like a physician in real life. & $3.6 \pm 0.7$ \\
\hline 2. While working on the virtual patient I felt like the physician in charge. & $3.4 \pm 0.8$ \\
\hline \multicolumn{2}{|l|}{ Professional approach } \\
\hline 3. I was actively involved in critically challenging my image about the patient when I got new information while working on the case. & $3.4 \pm 0.8$ \\
\hline 4. I was actively involved in summarizing the patients' clinical presentation in a few sentences while working on the case. & $3.6 \pm 0.8$ \\
\hline 5. I was actively thinking about weather my findings support or not support my differential diagnoses while working on the case. & $3.5 \pm 0.9$ \\
\hline \multicolumn{2}{|l|}{ Coaching } \\
\hline 6. The level of difficulty of the case was adjusted to my level of knowledge. & $3.8 \pm 0.7$ \\
\hline 7. The questions I was asked while working on the case were helpful to enhance my knowledge about the procedure in this case. & $4.0 \pm 0.7$ \\
\hline 8. The feedback I got while working on the case were helpful to enhance my knowledge about the procedure in this case. & $4.0 \pm 0.7$ \\
\hline 9. The embedded media (illustrations, video clips, interactive graphics) supported my learning of the procedure. & $4.1 \pm 0.8$ \\
\hline \multicolumn{2}{|l|}{ Learning effect } \\
\hline 10. After completion of the case I feel better prepared for performing this procedure on a real life patient. & $3.8 \pm 0.7$ \\
\hline 11. After completion of this case I feel better prepared for assuring the diagnosis and exclude important differential diagnoses on a real life patient. & $3.7 \pm 0.7$ \\
\hline \multicolumn{2}{|l|}{ Overall judgement } \\
\hline 12. Overall, the case was a worthwhile learning experience. & $4.0 \pm 0.7$ \\
\hline \multicolumn{2}{|l|}{ Open ended questions } \\
\hline \multicolumn{2}{|l|}{ 13. From your point of view, what are specific strengths of this case? } \\
\hline \multicolumn{2}{|l|}{ 14. From your point of view, what are specific weaknesses of this case? } \\
\hline 15. Other comments? & \\
\hline
\end{tabular}

\section{Blended learning approach}

The teaching presence received a very good rating by the students $(4.1 \pm 0.9)$. The cognitive preparation for $(4.2 \pm 0.7)$ and the social presence within the skills laboratory $(4.3 \pm 0.7)$ were very well perceived. Students felt a high learning effect $(4.0 \pm 0.7)$ and gave an overall judgement for the whole learning scenario of $4.3 \pm 0.7$ (Likert scales as before; Figure 4). Table 3 shows detailed results of all single items. The free-text entries revealed high acceptance for this kind of blended learning scenario. Several students specified that the VPs are well adjusted to the practical training and web-based training from home offers the possibility to invest time and effort individually as needed (e.g., when, where, and how long). VPs were perceived as a very good preparation.

\section{Tutors' perceptions}

Skills laboratory tutors perceived students as generally very well prepared for the skills laboratory training. According to the tutors, student groups usually did not need initial instructions and were able to start training right away. The tutors presumed that this was based on the interactive nature, multimedia support, showing of the complete procedure, and all given relevant information being implemented in the VP.

Tutors presumed that the interactive engagement with the VP in a very concrete way played a key role for the perceived high level of preparation. The general sequence of the procedure was usually clear to students, so only specific questions were posed. The tutors perceived the use of time as very efficient because students were hands-on the whole training time and feedback could be given during repetitive practice. The training sessions themselves were perceived as proceeding harmoniously with an open and positive atmosphere.

Tutors also perceived that the duration between the preparation with the VP and the skills training was of relevance. When the preparation was too long before the skills laboratory students' level of preparation considerably decreased.

\section{Discussion}

Skills laboratory training is an expensive teaching method because it takes supervision in small group tutorials with the corresponding need for numerous tutors and time slots in skills laboratories. Usually the face-to-face skills laboratory time is used for instruction, demonstrations, and repeated practice under supervision [3]. In this study we investigated how VPs as preparation for a paediatric skills laboratory were perceived by students and tutors and whether the preparation with VPs could substitute for the instruction and demonstration phase in the skills laboratory and in this way use the precious time of skills laboratory more effectively. 
Table 3 Blended learning questionnaire and results

\begin{tabular}{|c|c|}
\hline Category/items & Result \\
\hline \multicolumn{2}{|l|}{ Teaching presence } \\
\hline 1. I felt well informed about how the virtual patients were integrated into this course. & $4.1 \pm 0.7$ \\
\hline 2. The chronological order of the virtual patient work and the skills laboratory was well thought out. & $4.1 \pm 0.7$ \\
\hline 3. The time spent on the virtual patients was well balanced with the time spent in the skills laboratory. & $3.9 \pm 0.8$ \\
\hline 4. The content of virtual patients and the skills laboratory complemented each other well. & $4.3 \pm 0.6$ \\
\hline 5. The skills laboratory gave me an insightful learning experience, which I would not have had from the virtual patients alone. & $4.3 \pm 0.7$ \\
\hline 6. The virtual patients gave me an insightful learning experience, which I would not have had from the skills laboratory alone. & $3.6 \pm 1.0$ \\
\hline 7. I think that learning with the virtual patients is important in order to do well in the final exam for this course. & $3.8 \pm 0.9$ \\
\hline 8. I had easy access to the virtual patients at my convenience. & $3.8 \pm 1.2$ \\
\hline 9. The tutors helped me to assess my learning during the skills laboratory. & $3.9 \pm 0.8$ \\
\hline 10. The tutors facilitated the further development of my practical skills during the skills laboratory. & $4.3 \pm 0.8$ \\
\hline 11. The tutors were well prepared for the skills laboratory (incl. familiarity with the virtual patients). & $4.5 \pm 0.7$ \\
\hline \multicolumn{2}{|l|}{ Cognitive preparation } \\
\hline 12. I was actively involved in practical applying my newly gained insights during the skills laboratory. & $4.4 \pm 0.6$ \\
\hline 13. I was actively involved in refining my practical skills during the skills laboratory. & $4.3 \pm 0.7$ \\
\hline 14. Because of the preparation by virtual patients skills laboratory time could be used more effectively. & $4.1 \pm 0.8$ \\
\hline \multicolumn{2}{|l|}{ Social presence } \\
\hline 15. During the skills laboratory the tutors created a convenient atmosphere so I could discuss about my mistakes. & $4.1 \pm 0.8$ \\
\hline 16. I felt a positive climate for learning during the skills laboratory. & $4.4 \pm 0.7$ \\
\hline 17. I felt like part of a 'community' during the skills laboratory. & $4.3 \pm 0.7$ \\
\hline \multicolumn{2}{|l|}{ Learning effect } \\
\hline 18. The combination of virtual patients and skills laboratory enhanced my clinical practical skills. & $4.0 \pm 0.7$ \\
\hline 19. The combination of virtual patients and skills laboratory made me feel better prepared to care for a real life patient with this complaint. & $4.1 \pm 0.7$ \\
\hline \multicolumn{2}{|l|}{ Overall judgement } \\
\hline 20. Overall, the combination of virtual patients and corresponding teaching events was a worthwhile learning experience. & $4.3 \pm 0.7$ \\
\hline \multicolumn{2}{|l|}{ Open ended questions } \\
\hline \multicolumn{2}{|l|}{ 21. From your point of view, what are specific weaknesses of the overall virtual patient integration into this course? } \\
\hline 22. From your point of view, what are specific strengths of the overall virtual patient integration into this course? & \\
\hline 23. Please describe how an ideal integration of VP would look like in this context, from your point of view. & \\
\hline
\end{tabular}

Overall, both students and tutors well accepted the design and the curricular integration of VPs used as preparation for skills laboratory training. Both students and tutors perceived the presented approach as a useful and effective blend. Students felt well prepared by VPs and thus could efficiently use the skills laboratory time for practical training.

Results are consistent with other reports using VPs as preparation for communication training or for specific clinical examinations. Students are generally receptive to the use of electronic learning tools [21]. For example, Holzinger et al. showed that sophisticated e-simulations can be beneficial for learning complex concepts if they are well guided and fit to students' previous levels of knowledge [34]. The interaction with a VP prior to a real patient improved student confidence and reduced anxiety in performing breast examinations in a real patient encounter [20]. For teaching clinical skills a VP can be as effective as a standardised patient [22].
The innovative nature of our approach is to show the impact of an interactive preparation on the learning process in a skills laboratory. Other studies mainly focused on the learning outcome although the efficient use of tutor and skills laboratory time is becoming increasingly important as medical education faces restricted budgets and should thus not be neglected. In a study of communication skills training, Bosse et al. discussed costs and required resources in relation to the added value for peer role-play and standardised patients [35].

Carrero et al. reported that multimedia presentations or case-based discussions equally improved the level of cognitive skills in basic life-support training [24]. In contrast to the setting in our study the preparation with these multimedia presentations were either passive or an additional face-to-face session was required. One advantage of using VPs is to connect the attractiveness of multimedia and interactivity with the scenario of one specific patient. This makes access to the skill more 


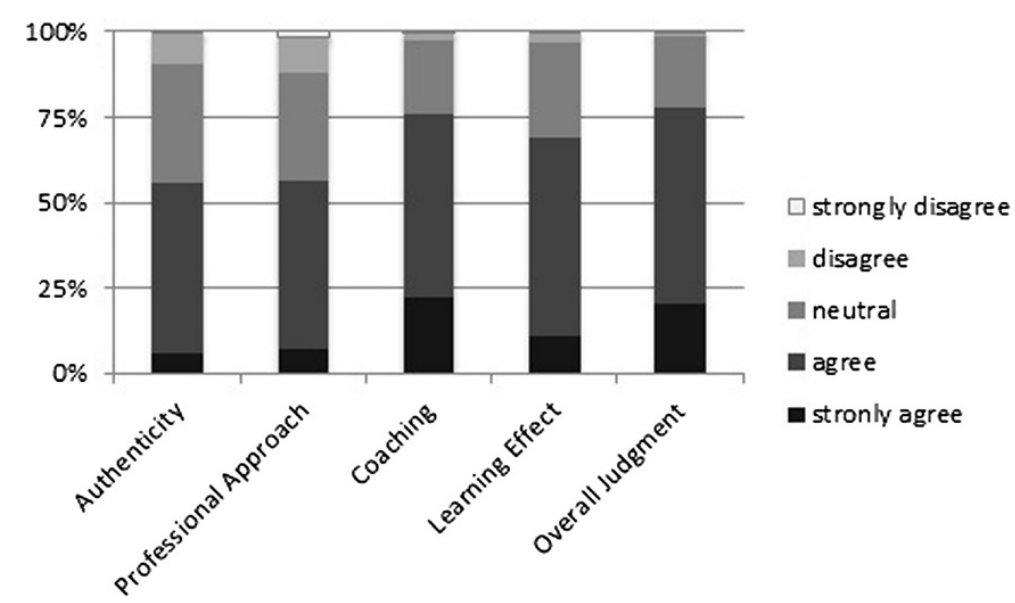

Figure 3 Category results of the VP design questionnaire. Category results of the VP design questionnaire (Likert scales from 1 - totally disagree to 5 - totally agree). Participants rated the VP design as authentic, as an acceptable professional approach, effective for coaching, and with a high learning effect. Overall judgement was very favourable.

transparent and understandable, and thus the clinical significance can be better understood. The presentation and explanation of a procedure within a clinical case seems to help students learn in context, to understand its clinical importance and role, to increase the perceived level of realism, and to enhance students' involvement [36]. Similarly, Lenchus et al. reported for postgraduate training that training of procedures using a blended learning scenario which employed videos in a sequence with discussions and skills training on mannequins significantly improved participants' knowledge and technical performance [25]. In contrast, our approach was efficient in the preparation for the skills laboratory without using the precious time of tutors in face-to-face discussions. In our study we assumed that we could substitute the introduction in our skills laboratory because critical points of the procedures had already been interactively worked through with questions and illustrations by videos, graphs, and figures within the VP. The participants had already seen the whole procedure in total as well as important details elaborated in the cases. This is in line with the publications of Carrero et al. and Lenchus et al. who showed that even watching a procedure is quite helpful for learning $[24,25]$. It is important to note that VPs do not substitute for tutors during the face-to-face training time in general, but only for the introductory information and demonstration part. When authoring VPs for such a task it is important to bear in mind that this is a special application area of VPs and design criteria might be different than in other

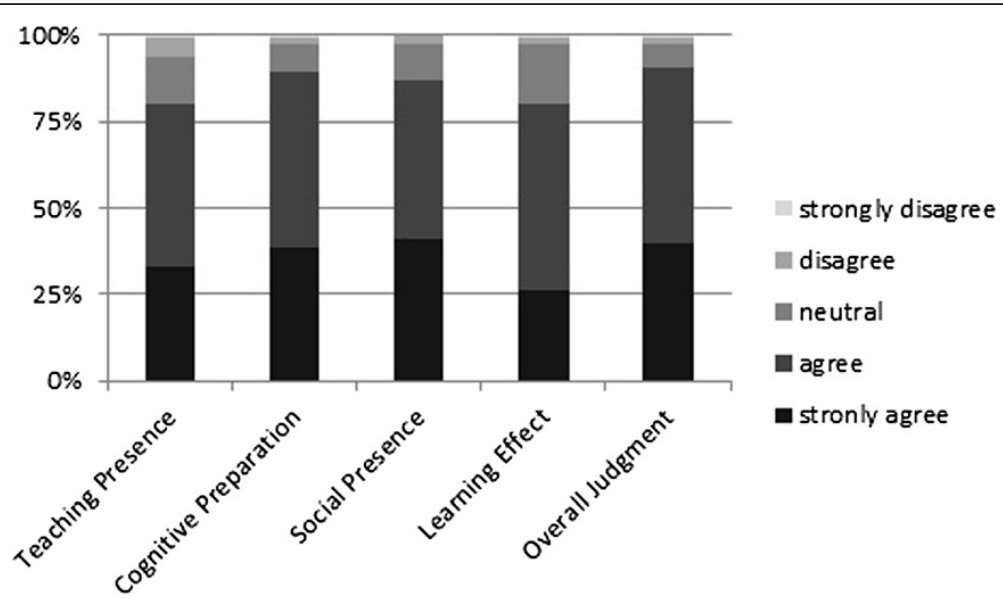

Figure 4 Category results of the blended learning questionnaire. Category results of the blended learning questionnaire (Likert scales from 1 - totally disagree to 5 - totally agree). Participants rated the blended learning scenario high for teaching presence, with a good cognitive preparation for and a good social presence in the skills lab. The learning effect was perceived effective and the overall judgement was very favourable. 
conditions where VPs are especially used to prepare for clinical reasoning.

We think we created a good example of blended learning which combines the best of both worlds: taking advantage of interactive multimedia VPs in self-study as preparation for supervised small-group practical training sessions. This accords with cognitive load theory which suggests that reducing cognitive load during face-to-face-training results in a better learning outcome [6]. We assumed that we could reduce cognitive load during the face-to-face sessions by the preceding work-up of VPs. Strengths of this study include triangulation of judgements with using students' feedback by means of questionnaires and tutor feedback by interviews. Because this study was a study on Kirkpatrick's first level [37] further studies are needed to assess the effect of this kind of training and the sustainability of such an approach.

\section{Conclusions}

Our results indicate that multimedia-enhanced VPs as described in this study offer a useful preparation for practical skills training. Through prior cognitive preparation training time was used efficiently in the skills laboratory. Future research should investigate how VPs should be designed and integrated to optimally prepare students for skills laboratory training. Furthermore, it would be interesting to compare different blended learning approaches concerning time, effort, and cost effectiveness, as well as performance improvement and sustainability.

\section{Competing interests}

The authors declare that they have no competing interests.

\section{Authors' contributions}

$\mathrm{RL}$ and $\mathrm{HMB}$ developed and introduced the blended learning scenario to the curriculum. AS supported the development of the VP and accomplished the students' evaluation. CN was responsible for the realisation within the longitudinal skills lab project at the medical school. SH was responsible for the scientific evaluation and study design. All authors read and approved the final manuscript.

\section{Authors' information \\ Ronny Lehmann, MD, is resident and in charge for skills laboratory training at the Centre for Child and Adolescent Medicine Heidelberg, Germany. Hans \\ Martin Bosse, MD, MME, is paediatric consultant and in charge of educational affairs at the Centre for Child and Adolescent Medicine Düsseldorf, Germany. Anke Simon, MD, is resident and jointly responsible for skills laboratory training at the Centre for Child and Adolescent Medicine Heidelberg, Germany. Christoph Nikendei, MD, MME, is internal medicine consultant and responsible for final year medical education at the Medical Hospital and the longitudinal skills laboratory curriculum at Heidelberg Medical School. Sören Huwendiek, MD, MME (Bern), is a paediatrician and was until recently chair of educational affairs at the Centre for Child and Adolescent Medicine Heidelberg, Germany, chair of the Centre for Virtual Patients and e-learning commissioner at Heidelberg Medical School. He is now head of the Department of Assessment and Evaluation at the Institute of Medical Education in Bern, Switzerland.}

\section{Author details}

${ }^{1}$ Clinic I - General Paediatrics, Centre for Child and Adolescent Medicine, Im Neuenheimer Feld 430, Heidelberg 69120, Germany. ${ }^{2}$ Department of General Paediatrics, Centre for Child and Adolescent Medicine, Moorenstr. 5,
Düsseldorf 40225, Germany. ${ }^{3}$ Department of Internal Medicine, University Hospital Heidelberg, Im Neuenheimer Feld 400, Heidelberg 69120, Germany. ${ }^{4}$ Department of Assessment and Evaluation, Institute of Medical Education, Faculty of Medicine, University of Bern, Konsumstrasse 13, Bern 3010, Switzerland.

Received: 31 July 2012 Accepted: 14 January 2013 Published: 12 February 2013

\section{References}

1. Issenberg SB, McGaghie WC, Petrusa ER, Lee GD, Scalese RJ: Features and uses of high-fidelity medical simulations that lead to effective learning: a BEME systematic review. Med Teach 2005, 27:10-28.

2. Nikendei $C$, Weyrich $P$, Jünger J, Schrauth M: Medical education in Germany. Med Teach 2009, 31:591-600.

3. Lynagh M, Burton R, Sanson-Fisher R: A systematic review of medical skills laboratory training: where to from here? Med Educ 2007, 41:879-887.

4. Krautter M, Weyrich P, Schultz J, Buss SJ, Maatouk I, Jünger J, Nikendei C: Effects of Peyton's four-step approach on objective performance measures in technical skills training: a controlled trial. Teach Learn Med 2011, 23:244-250.

5. Sweller J, van Merrienboer JJ, Paas F: Cognitive architecture and instructional design. Educ Psychol Rev 1998, 10:251-296.

6. van Merriënboer JJ, Sweller J: Cognitive load theory in health professional education: design principles and strategies. Med Educ 2010, 44:85-93.

7. Kruppa E, Jünger J, Nikendei C: Concept of a longitudinal skills Lab curriculum. In Research in medical education congress - chances and challenges, 20-22052009. Heidelberg: German Medical Science GMS Publishing House, Düsseldorf; 2009.

8. McGaghie WC, Issenberg SB, Petrusa ER, Scalese RJ: A critical review of simulation-based medical education research: 2003-2009. Med Educ 2010, 44:50-63.

9. Motschnig-Pitrik R, Holzinger A: Student-centered teaching meets New media: concept and case study. Educational Technology \& Society 2002, 5:160-172.

10. Ellaway R, Candler C, Greene P, Smothers V: An architectural model for MedBiquitous virtual patients. Baltimore: MD: MedBiquitous; 2006.

11. Huwendiek S, de Leng BA, Zary N, Fischer MR, Ruiz JG, Ellaway R: Towards a typology of virtual patients. Med Teach 2009, 31:743-748.

12. Cook DA, Triola MM: Virtual patients: a critical literature review and proposed next steps. Med Educ 2009, 43:303-311.

13. Friedman CP: The research we should be doing. Acad Med 1994, 69:455-457

14. Cook DA: The research we still are not doing: an agenda for the study of computer-based learning. Acad Med 2005, 80:541-548.

15. Triola MM, Huwendiek S, Levinson AJ, Cook DA: New directions in elearning research in health professions education: report of two symposia. Med Teach 2012, 34:e15-20.

16. Fischer MR, Hege I, Hörnlein A, Puppe F, Tönshoff B, Huwendiek S: Virtual patients in medical education: a comparison of various strategies for curricular integration. Z Evid Fortbild Qual Gesundhwes 2008, 102:648-653.

17. Hege I, Ropp V, Adler M, Radon K, Mäsch G, Lyon H, Fischer MR: Experiences with different integration strategies of case-based elearning. Med Teach 2007, 29:791-797.

18. Berman N, Fall LH, Smith S, Levine DA, Maloney CG, Potts M, Siegel B, Foster-Johnson L: Integration strategies for using virtual patients in clinical clerkships. Acad Med 2009, 84:942-949.

19. Edelbring S, Broström O, Henriksson P, Vassiliou D, Spaak J, Dahlgren LO, Fors U, Zary N: Integrating virtual patients into courses: follow-up seminars and perceived benefit. Med Educ 2012, 46:417-425.

20. Deladisma AM, Gupta M, Kotranza A, Bittner JG, Imam T, Swinson D, Gucwa A, Nesbit R, Lok B, Pugh C, et al: A pilot study to integrate an immersive virtual patient with a breast complaint and breast examination simulator into a surgery clerkship. Am J Surg 2009, 197:102-106.

21. Deladisma AM, Johnsen K, Raij A, Rossen B, Kotranza A, Kalapurakal M, Szlam S, Bittner JG, Swinson D, Lok B, et al: Medical student satisfaction using a virtual patient system to learn history-taking communication skills. Stud Health Technol Inform 2008, 132:101-105.

22. Triola M, Feldman H, Kalet AL, Zabar S, Kachur EK, Gillespie C, Anderson M, Griesser C, Lipkin M: A randomized trial of teaching clinical skills using virtual and live standardized patients. J Gen Intern Med 2006, 21:424-429. 
23. Edelbring S, Dastmalchi M, Hult H, Lundberg IE, Dahlgren LO: Experiencing virtual patients in clinical learning: a phenomenological study. Adv Health Sci Educ Theory Pract 2011, 16:331-345.

24. Carrero E, Gomar C, Penzo W, Fábregas N, Valero R, Sánchez-Etayo G: Teaching basic life support algorithms by either multimedia presentations or case based discussion equally improves the level of cognitive skills of undergraduate medical students. Med Teach 2009, 31:e189-195.

25. Lenchus J, Issenberg SB, Murphy D, Everett-Thomas R, Erben L, Arheart K, Birnbach DJ: A blended approach to invasive bedside procedural instruction. Med Teach 2011, 33:116-123.

26. Ventre KM, Collingridge DS, DeCarlo D: End-user evaluations of a personal computer-based pediatric advanced life support simulator. Simul Healthc 2011, 6:134-142.

27. Bonk CJ, Graham CR: Handbook of blended learning: global perspectives, local designs. San Francisco: Pfeiffer Publishing; 2006.

28. Huwendiek S, Reichert F, Bosse HM, de Leng BA, van der Vleuten CP, Haag M, Hoffmann GF, Tönshoff B: Design principles for virtual patients: a focus group study among students. Med Educ 2009, 43:580-588

29. Huwendiek S, Hanebeck B, Bosse HM, Haag M, Hoffmann GF, Tönshoff B: Learning and assessment with virtual patients at the University children's hospital Heidelberg: results of an evaluation for the "ELearning award Baden-Württemberg" 2007. GMS Med Inform Biom Epidemiol 2007, 5:Doc10.

30. Bosse HM, Wittekindt B, Höffe J: Pediatrics exams. Monatssch Kinderheilkd 2008, 156:467-472

31. Garde S, Bauch M, Haag M, Heid J, Huwendiek S, Ruderich F, Singer R, Leven F: CAMPUS - computer-based training in medicine as part of a problem-oriented educational strategy. Stud LEID 2005, 2:10-19.

32. Huwendiek S, de Leng BA: Virtual patient design and curricular integration evaluation toolkit. Med Educ 2010, 44:519.

33. Mayring P: Qualitative Inhaltsanalyse: Grundlagen und Techniken. 11th edition. Weinheim \& Basel: Beltz; 2010

34. Holzinger A, Kickmeier-Rust MD, Wassertheurer S, Hessinger M: Learning performance with interactive simulations in medical education: lessons learned from results of learning complex physiological models with the HAEMOdynamics SIMulator. Comput Educ 2009, 52:292-301.

35. Bosse HM, Nickel M, Huwendiek S, Jünger J, Schultz JH, Nikendei N: Peer role-play and standardised patients in communication training: a comparative study on the student perspective on acceptability, realism, and perceived effect. BMC Med Educ 2010, 10:27.

36. Nikendei C, Zeuch A, Dieckmann P, Roth C, Schäfer S, Völkl M, Schelleberg D, Herzog W, Jünger J: Role-playing for a more realistic technical skills training. Med Teach 2005, 27:122-126.

37. Kirkpatrick DL, Kirkpatrick JD: Evaluating Training Programs - The four Levels. 3rd edition. New York: Mcgraw-Hill Professional; 2006.

doi:10.1186/1472-6920-13-23

Cite this article as: Lehmann et al: An innovative blended learning approach using virtual patients as preparation for skills laboratory training: perceptions of students and tutors. BMC Medical Education 2013 13:23.

\section{Submit your next manuscript to BioMed Central and take full advantage of:}

- Convenient online submission

- Thorough peer review

- No space constraints or color figure charges

- Immediate publication on acceptance

- Inclusion in PubMed, CAS, Scopus and Google Scholar

- Research which is freely available for redistribution 